\title{
1 Effect of pressure on the crystal structure of ettringite
}

2

3 S.M. Clark ${ }^{\mathrm{a}^{*}}$, B. Colas ${ }^{\mathrm{a}}$, M. Kunz ${ }^{\mathrm{a}}$, S. Speziale ${ }^{\mathrm{b}}$, P.J.M. Monteiro ${ }^{\mathrm{c}}$

4

\section{Abstract}

13 X-ray diffraction and infrared data have been collected from a sample of ettringite from ambient

14 pressure to $6.4 \mathrm{GPa}$. The sample was found to reversibly transform to an amorphous phase at 3

$15 \mathrm{GPa}$. The isothermal bulk modulus of ettringite was found to be $27(7) \mathrm{GPa}$ and the 16 incompressibilities of the lattice parameters were found to be 71(30) GPa along a and 108(36)

17 GPa along $\mathbf{c}$.

Keywords:

${ }^{a}$ Advanced Light Source, Lawrence Berkeley National Laboratory, 1 Cyclotron Road, Berkeley, CA94720.

${ }^{b}$ GeoForschungsZentrum Potsdam, GeoForschungsZentrum Potsdam, Division 4.1, Telegrafenberg, 9, Potsdam, 14473 Germany.

'University of California, Berkeley, Department of Civil and Environmental Engineering, 725 Davis Hall, University of California, CA94720. 
30 with a large proportion of interconnected void space allowing some mobility of water and hydrated

31 ions. The ettringite structure is quite flexible allowing interchange of atomic species resulting in

32 the structure being adopted by other minerals with through series solid solution [9] and potential

33 applications in waste management [10].

34 The thermal dehydration of ettringite has been studied $[11,12,13,14]$ with some disagreement

35 over the exact order of hydroxyl and free water leaving the crystal but general agreement over a

36 large water loss at $110^{\circ} \mathrm{C}$ followed by amorphization of the sample after the loss of 20 water units.

37 Given that $80 \%$ of the atoms in this mineral are either part of a water molecule or an hydroxide,

38 resulting in a specific gravity of 1.7 one could regard ettringite as being almost all water and as

39 such might expect it to be an extremely soft solid and potentially unstable under compression.

40 Here we report the results of a x-ray and infrared study of the effect of pressure on the crystal

41 structure of ettringite. Although the pressures that our ettringite sample was subjected to in this

42 study are much higher than could exist in a cement paste this approach to studying the stability of

43 cement phases is important since it gives us insight into the underlying factors controlling phase

44 stability and helps us understand the possible mechanisms controlling reactivity by analogy to

45 simpler systems.

\section{2. Experimental}

48 The samples investigated in this study were obtained from a natural sample of ettringite from

49 N'Chwanning mine, Kurruman, South Africa [15]. The sample was characterized by laboratory

50 powder $\mathrm{X}$-ray diffraction. The measured unit-cell parameters are $a_{0}=11.240 \pm 0.001 \AA$, $c_{0}=$

$5121.468 \pm 0.006 \AA$, in good agreement with values from the literature $[5,6]$. A transparent,

52 prismatic fragment $5 \mathrm{~mm}$ long and $2 \mathrm{~mm}$ wide was picked from a larger specimen and ground to a

53 fine powder of about $5 \mu \mathrm{m}$ particle size.

55 High-pressures were generated using diamond anvil cells (dacs). Typical features of a dac are

56 shown in figure 2. Samples are contained between two opposed diamonds. A thin metal foil is

57 pressed between the diamonds and a hole drilled in the center to give a sample chamber. The 
58 sample together with a few chips of ruby, which are used to determine pressure, and a pressure

59 transmitting fluid are loaded into the hole in the gasket. Pressing the diamonds together

60 decreases the sample chamber volume and increases the pressure.

62 Pressure volume data were obtained by powder X-ray diffraction at beamline 12.2 .2 at the 63 Advanced Light Source (ALS). This beamline benefits from hard x-radiation generated by a 64 superbend magnet. The beamline operates in angle dispersive geometry (monochromatic) and is 65 equipped with an image plate detector and suitable collimation and goniometry for powder 66 diffraction measurements from samples held in diamond anvil cells [16]. Data were collected 67 using $\mathrm{X}$-radiation of $15 \mathrm{keV}$ energy (wavelength $\lambda=0.82653 \AA$ ). The beam size at the sample 68 was set at $20 \times 20 \mu \mathrm{m}^{2}$ in order to ensure that no diffraction from the gasket material 69 contaminated our diffraction patterns. Any scatter from our focusing optics was removed using $70100 \mu \mathrm{m}$ Ta cleanup pinhole positioned about $60 \mathrm{~mm}$ in front of the diamond anvil cell. Exposure 71 times of 300 s were found to be sufficient to give powder diffraction patterns of adequate signal to 72 noise ratio. Powder diffraction data were collected at a total of 14 pressure points in two separate 73 runs. For both runs, a small amount of the powdered ettringite sample was loaded into a $250 \mu m$ 74 hole in a stainless steel gasket $(250 \mu \mathrm{m}$ thickness, pre-indented to $70 \mu \mathrm{m})$ together with a ruby 75 sphere for pressure determination $[17,18]$. In both runs a membrane diamond anvil cell equipped 76 with $500 \mu \mathrm{m}$ culet diamonds (1.6 mm height) and WC-backing plates was used. For the first run 77 (10 pressure points) we used silicone oil as pressure medium whereas in the second run (4 78 pressure points) the sample was embedded in a 4:1 mixture of methanol:ethanol. In both runs 79 diffraction patterns were collected while both increasing as well as decreasing pressure. 80 Pressure was measured off-line using the ruby fluorescence method. The $488 \mathrm{~nm}$ line of an Ar81 ion laser was used to excite the fluorescence of the ruby crystal loaded into the gasket sample.

82 The pressure dependent fluorescence line was measured using a Roper Scientific spectrometer 83 and analyzed using the WinView software supplied by Roper Scientific. 
85 High-pressure infrared data were collected at beamline 1.4 .3 of the advanced light source $86[19,20,21]$. The infrared beam is collimated to about $10 \mu \mathrm{m}$ in diameter. Spectra were collected 87 using a Nicolet Magna $760 \mathrm{FTIR}$ spectrometer with a resolution of $4 \mathrm{~cm}^{-1}$. A special low profile 88 diamond anvil cell suitable for use with the Nicolet spectrometer was used to generate high89 pressures. The cell used $300 \mu m$ culets and type 1a diamonds. Samples were contained in a

$90150 \mu \mathrm{m}$ hole drilled into a stainless steel gasket. The gasket hole was first filled with $\mathrm{KBr}$ which 91 had been dried for three days at $150^{\circ} \mathrm{C}$ in a vacuum oven. The $\mathrm{KBr}$ sample was compressed 92 between the diamonds to give a well packed gasket hole. A small amount of the $\mathrm{KBr}$ was then 93 removed from and the sample and one or two ruby chips were then packed into this small hole.

94 Pressures were measured using the ruby fluorescence method. The ruby chips were placed 95 close to the sample in order to minimize errors in pressure measurement. Prior to the acquisition 96 of each sample spectrum a background spectrum was collected in an area of the $\mathrm{KBr}$ where there 97 was no sample. Subsequently, a spectrum was collected from the sample from which the 98 background spectrum was subtracted. Spectra were collected with increasing pressure from 99 ambient to $6.4 \mathrm{GPa}$ and then with decreasing pressure to ambient. A number of extra pressure 100 cycles were performed to check the reproducibility of our results.

101

\section{3. Results}

103 An ambient pressure powder diffraction pattern from ettringite held in a diamond anvil cell is 104 shown in figure 3. The shadow of the $\mathrm{x}$-ray backstop is visible in the center of the pattern as well 105 as the diffraction rings from the sample. All of our X-ray data were radially integrated to give two 106 dimensional powder diffraction patterns using the fit2d program [22] using beam center, detector 107 tilt and sample to detector distance determined using fit2d from a powder diffraction pattern from 108 the NBS $\mathrm{LaB}_{6}$ powder diffraction standard. The result of integrating the ambient pattern of figure 3

109 is shown in figure 4. All diffraction peaks were found to originate from the sample except for a 110 peak at about $7 \AA$ which we were unable to assign. The result of a weighted LeBail fit to the 111 ambient data using the Hartman and Berliner [8] structure as a starting point is shown in figure 4.

112 The background was modeled with a shifted Chebeyshev function, peak profiles were fitted using 
113 a pseudo-Voigt function [23]. We obtained an adequate fit to our data which yielded lattice 114 parameters of $11.2422(4) \AA$ for a and 21.496(1) $\AA$ for $\mathbf{c}$ (where the number in parentheses is the

$1151 \sigma$ uncertainty in the last digit) which compare well with the literature values of $11.26 \AA$ and 21.48

$116 \AA[5,6]$ although they do deviate somewhat from the Hartman and Berliner values of $11711.166881(82) \AA$ and 21.35366(22) $\AA$ [8]. The effect of pressure on the diffraction pattern of 118 ettringite can be seen in figure 4 which contains a stack plot of the diffraction patterns collected 119 using silicone oil as a pressure transmitting fluid. On increasing pressure to $1.2 \mathrm{GPa}$ the 120 diffraction peaks are seen to move to lower d-spacing, as the unit cell volume decreases, but the 121 overall diffraction pattern does not show any significant change. At $2.4 \mathrm{GPa}$ the peaks broaden 122 and weaken and at $3.7 \mathrm{GPa}$ are all gone except for a broad peak at about $9 \AA$. On decreasing 123 pressure the broadened peaks are found to reappear. We were able to obtain satisfactory 124 weighted LeBail fits to our $0.5 \mathrm{GPa}$ and $1.2 \mathrm{GPa}$ diffraction patterns (table 1) but no satisfactory fit 125 could be obtained with the subsequent patterns. An estimate of the bulk modulus of ettringite and 126 incompressibility of the lattice parameters was made by linear fit to the pressure dependence of 127 the unit cell volume and lattice parameters that we determined (figure 6). The isothermal bulk 128 modulus of ettringite was found to be $27(7) \mathrm{GPa}$ and the incompressibilities of the lattice 129 parameters were found to be $71(30) \mathrm{GPa}$ along the a-direction and $108(36) \mathrm{GPa}$ along the c130 direction. Data were also collected using a 4:1 methanol:ethanol mixture as a pressure 131 transmitting medium instead of silicone oil in order to check if the sample environment has any 132 effect on these transitions. The general behavior was found to be the same with the peaks 133 broadening, disappearing and reappearing but the lattice parameters that we obtained differed 134 markedly from those obtained in silicone oil.

136 An infrared spectrum collected from an ettringite sample held in a diamond anvil cell at ambient 137 pressure is shown in figure 7. Strong absorption lines from the diamonds are seen between 1800 138 and $2600 \mathrm{~cm}^{-1}$. We assign the sharp absorption at $3634 \mathrm{~cm}^{-1}$ as being due to non-hydrogen 139 bonded $\mathrm{O}-\mathrm{H}$ stretch, the broad absorption at $3422 \mathrm{~cm}^{-1}$ as due to hydrogen bonded $\mathrm{O}-\mathrm{H}$ stretch 140 and free water, the peak at $1674 \mathrm{~cm}^{-1}$ as due to $\mathrm{O}-\mathrm{H}$ bend and the peak at $1108 \mathrm{~cm}^{-1}$ as due to S- 
$141 \mathrm{O}$ stretch from $\mathrm{SO}_{4}{ }^{2-}$ groups in line with previous assignations [24-27]. The effect of pressure on 142 the infrared spectrum of ettringite is shown in figure 8 . In the $\mathrm{O}-\mathrm{H}$ stretch region (figure 8a) the 143 non-hydrogen bonded $\mathrm{O}-\mathrm{H}$ stretch absorbance is seen to decrease with increasing pressure and 144 disappear at about $3 \mathrm{GPa}$. At the same time the broad hydrogen bonded absorption further 145 broadens up to the maximum pressure of $6.4 \mathrm{GPa}$. On decreasing pressure the broad hydrogen

146 bonded absorption is seen to sharpen and the non-hydrogen bonded absorption reappears to 147 give a spectrum that is very similar to the original ambient spectrum. In the low frequency section 148 of the spectra (figure $8 \mathrm{~b}$ ) we see the $\mathrm{O}-\mathrm{H}$ stretch band broaden with pressure and sharpen on 149 pressure release while the sulfate band does not change in width or intensity but moves to lower 150 frequency on pressurization and higher frequency on pressure release. The position of the 151 sulfate band as a function of pressure is shown in figure 9. The band is seen to linearly increase 152 in frequency at a rate of about $12 \mathrm{~cm}^{-1} / \mathrm{GPa}$ until about $3 \mathrm{GPa}$ when it then linearly increases at a 153 rate of about $5.9 \mathrm{~cm}^{-1} / \mathrm{GPa}$.

\section{4. Discussion}

156 Both the infrared and diffraction data show a transformation in ettringite at about $3 \mathrm{GPa}$. The $\mathrm{x}-$ 157 ray data show the structure of ettringite transforming to a distorted version of the ambient crystal 158 structure and then losing long range order as the pressure is increased ending up with only a 159 broad basal reflection. We interpret this as being due to strain on the crystal structure inducing 160 increasing amounts of disorder leading to amorphization. The return of $x$-ray diffraction peaks 161 indicates that the crystalline to amorphous transition is reversible. Our data indicate that this is a 162 continuous transition but further data collection with a finer pressure sampling is required to 163 confirm this. The infrared data give us some indication of the mechanism of this amorphization. 164 We see a decrease in the number of hydroxyl groups that are non-hydrogen bonded and an 165 increase in the width of the hydrogen bonded $\mathrm{O}-\mathrm{H}$ stretch peak. This we interpret as being due to 166 an increased number of hydroxyl bonding environments as the crystal structure becomes more 167 disordered. The sulfate S-O stretch band moves to higher frequency with increasing pressure 168 which we interpret as being due to bond shortening but remains intact through out the 
169 amorphization and re-crystallization. We interpret this as indicating that the basic structural units 170 within the crystal structure remain intact but disorder with respect to each other and the free water 171 in the structure. We can not tell if the amorphization is associated with dehydration of the 172 structure as happens during thermal decomposition [14] but the prevalence of the hydroxyl bands 173 and the reversibility of the transitions suggest that no dehydration occurs. $\mathrm{Ca}(\mathrm{OH})_{2}[28], \mathrm{Ni}(\mathrm{OH})_{2}$

174 and $\mathrm{Co}(\mathrm{OH})_{2}$ [29] all exhibit a reversible pressure induced amorphization near 11GPa. These 175 amorphizations have been found to be caused by disruption of the network of hydrogen bonds 176 [30]. This may also be the case for ettringite.

177

\section{Acknowledgements}

179 The Advanced Light Source is supported by the Director, Office of Science, Office of Basic

180 Energy Sciences, of the U.S. Department of Energy under Contract No. DE-AC02-05CH11231.

181 This research was partially supported by COMPRES, the Consortium for Materials Properties

182 Research in Earth Sciences under NSF Cooperative Agreement EAR 01-35554.

183

184 
186 [1] H.F.W. Taylor, Cement Chemistry, Thomas Telford, London, 1997.

187 [2] M. Santhanam, M.D. Cohen, and J. Olek, Sulfate attack research - whither now?, Cement and 188 Concrete Research 31 (2001) 845-851.

189 [3] H.F.W. Taylor, C. Famy, K.L. Scrivener, Delayed ettringite formation, Cement and Concrete

190 Research 31 (2001) 683-693.

191 [4] P.K. Mehta and P.J.M. Montiero, Concrete: Microstructure, Properties and Materials, third 192 edition, McGraw-Hill, 2006.

193 [5] A.E. Moore and H.F.W. Taylor, Crystal Structure of Ettringite, Nature 218 (1968) 1048-1049.

194 [6] A.E. Moore and H.F.W. Taylor, Crystal Structure of Ettringite, Acta Cryst., B26 (1970) 386195393.

196 [7] R. Berliner, The structure of ettringite, Materials Science of Concrete - The Sydney Diamond 197 Symposium Eds. M. Cohen, S. Mindness and J. Skalny, 1998, pp127-141.

198 [8] M.R. Hartman and R. Berliner, Investigation of the structure of ettringite by time-of-flight 199 neutron powder diffraction techniques, Cement and Concrete Research 36 (2006) 364-370.

200 [9] S.J. Barnett, C.D. Adams and A.R.W. Jackson, Solid Solution between Ettringite $201 \mathrm{Ca}_{6} \mathrm{Al}_{2}\left(\mathrm{SO}_{4}\right)_{3}(\mathrm{OH})_{12} \cdot 26 \mathrm{H}_{2} \mathrm{O}$ and Thaumasite $\mathrm{Ca}_{3} \mathrm{SiSO}_{4} \mathrm{CO}_{3}(\mathrm{OH})_{6} \cdot 12 \mathrm{H}_{2} \mathrm{O}$, Journal of Materials 202 Science 35 (2000) 4109-4114.

203 [10] G.J. McCarthy, D.J. Hassett and J.A. Bender, Synthesis, crystal structure and stability of 204 ettringite, a material with potential applications in hazardous waste immobilization, Advanced 205 Cementitious Systems: Mechanisms and Properties, Materials Research Society Synposium 206 Proceedings Series 245 (1992) 129-140.

207 [11] Y. Shimada and J.F. Young, Structural changes during thermal dehydration of ettringite Adv. 208 Cement Res. 13 (2001) 77-81.

209 [12] N.N. Skoblinskaya and K.G. Krasilnikov, Changes in crystal structure of ettringite on 210 dehydration 1. Cement and Conrete Research 5 (1975) 381-394.

211 [13] N.N. Skoblinskaya, K.G. Krasilnikov, L.V. Nikitina and V.P. Varlamov, Changes in crystal 212 structure of ettringite on dehydration 2. Cement and Concrete Research 5 (1975) 419-432. 
213 [14] M.R. Hartman, S.K. Brady, R. Berliner and M.S. Conradi, The evolution of structural changes 214 in ettringite during thermal decomposition, Journal of Solid State Chemistry 179 (2006) 12592151272.

216 [15] B. Cairncross, N.J. Beukes and J. Gutzmer, The manganese adventure: The South African 217 manganese field, Johannesburg, Associated Ore and Metal Corporation (1997) pp236.

218 [16] M. Kunz, A.A. MacDowell, W.A. Caldwell, D. Cambie, R.S. Celestre, E.E. Domning, R.M.

219 Duarte, A.E. Gleason, J.M. Glossinger, N. Kelez, D.W. Plate, T. Yu, J.M. Zaug, H.A. Padmore, R. 220 Jeanloz, A.P. Alivisatos, and S.M. Clark, A beamline for high pressure studies at the Advanced 221 Light Source with a superconducting bending magnet as the source, J. Synch. Rad. 12(5) (2005) $222 \quad 650-658$.

223 [17] H-K. Mao, J. Xu and P.M. Bell, Journal of Geophysical research - Solid Earth and Planets. 22491 B5 (1986) $4673-4676$.

225 [18] G.J. Piermarini, S. Block, J.D. Barnett and R.A. Forman, Journal of Applied Physics. 46(6) 226 (1995) 2774-2780.

227 [19] W.R. McKinney, C.J. Hirschmugl, H.A. Padmore, T. Lauritzen, N. Andresen, G. Andronaco, 228 R. Patton, and M. Fong, The First Infrared Beamline at the ALS: Design, Construction, and 229 Commissioning, SPIE Proceedings 3153 (1997) 59-76.

230 [20] M.C. Martin and W.R. McKinney, The First Synchrotron Infrared Beamlines at the Advanced 231 Light Source: Microspectroscopy and Fast Timing, Proc. Mater. Res. Soc. 524 (1998) 11.

232 [21] W.R. McKinney, M.C. Martin, J. Byrd, R. Miller, M. Chin, G. Portman, E.J. Moler, T. 233 Lauritzen, J.P. McKean, M. West, N. Kellogg, V. Zhuang, P.N. Ross, J.W. Ager III, W. Shan, E.E. 234 Haller, The First Infrared Beamlines at the ALS: Final Commissioning and New End Stations, 235 SPIE Proceedings 3775 (1999) 37-43.

236 [22] A.P. Hammersley, S.O. Svensson, M. Hanfland, A.N. Fitch and D. Hausermann, Two237 dimensional detector software: From real detector to idealized image or two-theta scan, High 238 Pressure Research 14 (1996) 235-248. 
240 [23] B.H. Toby, EXPGUI, a graphical user interface for GSAS, J. Appl. Cryst. 34 (2001) 210-213.

242 [24] S.J. Barnett, D.E. Macphee, E.E. Lachowski and N.J. Crammond, XRD, EDX and IR analysis 243 of solid solutions between thaumasite and ettringite, Cement and Concrete Research 32 (2002) $244 \quad 719-730$.

246 [25] S.C.B. Myneni, S.J. Traina, G.A. Waychunas and T.J. Logan, Vibrational spectroscopy of

247 functional group chemistry and arsenate coordination in ettringite, Geochimica et Cosmochimica $248 \quad$ Acta 62 (1998) 3499-3514.

250 [26] M.Y.A. Mollah, F. Lu and D.L. Cocke, An x-ray diffraction and Fourier transform infrared 251 spectroscopic characterization of the speciation of arsenic (V) in Portland cement type- $\mathrm{V}$, The 252 Science of the Total Environment 224 (1998) 57-68.

254 [27] M.A. Trezza and A.E. Lavat, Cement and Concrete Ressearch 31 (2001) 869-872.

256 [28] C. Meade and R. Jeanloz, Geophys. Res. Lett. 17 (1990) 1157-1160.

258 [29] J.H. Nguyen, M.B. Kruger and R. Jeanloz, Phys. Rev. B. 49 (1994) 3734-3738.

260 [30] T.S. Duffy, R.J. Hemley and H-K. Mao, "Deep Earth and Planetary Volatiles: AIP, New York, 2611994 


\section{Figure captions}

Fig. 1 Crystal structure of ettringite projected on to the (0001) plane [6]. $\mathrm{Ca}_{6}\left[\mathrm{Al}_{2}(\mathrm{OH})_{12} \cdot 24 \mathrm{H}_{2} \mathrm{O}\right]^{6+}$ columns lie parallel to the c-axis with sulfate and water molecules in the inter-column channels. Ca atoms are displayed as blue circles, oxygen atoms in red, aluminum atoms in light blue, sulfate tetrahedral in yellow and hydrogen atoms in grey.

Fig. 2 Schematic diagram of a diamond anvil cell.

Fig. 3 Raw 2-dimensional powder diffraction pattern from an ettringite sample contained in a diamond anvil cell at ambient pressure prior to reduction to a 1-dimensional pattern using the fit2d [18] program.

Fig. 4 1-dimensional powder pattern from an ettringite sample contained in a diamond anvil cell at ambient pressure together with a simulated pattern, calculated from a LeBail fit to our data, and a difference plot. Vertical tick marks show the predicted positions of diffraction peaks.

Fig. 5 Stack plot showing x-ray powder diffraction patterns collected from an ettringite sample at increasing pressures from ambient to $3.7 \mathrm{GPa}$ and decreasing pressure from 3.7 to 1.1GPa.

Fig. 6 Lattice parameters ( $a$ and $b$ ) and volume (c ) determined for ettringite as a function of pressure. Linear fits to these data were used to estimate the isothermal bulk modulus and the two linear incompressibilities along the $\mathbf{a}$ and $\mathbf{c}$ directions.

Fig. 7 Ambient infrared pattern collected from a sample of ettringite at ambient pressure in a diamond anvil cell. The strong absorption bands between 1800 and $2600 \mathrm{~cm}^{-1}$ are due to absorption by the diamonds.

Fig. 8 Variation of the infrared absorbance as a function of pressure in the $3000-3800 \mathrm{~cm}^{-1}$ (a) and $900-1800 \mathrm{~cm}^{-1}(\mathrm{~b})$ ranges.

Fig. 9 Variation of the sulfate infrared absorption band of ettringite as a function of pressure. 


\section{Table caption}

Table. 1 Results of a LeBail fit to our data using the GSAS program.

268

269

270 
$271 \quad$ Fig. 1

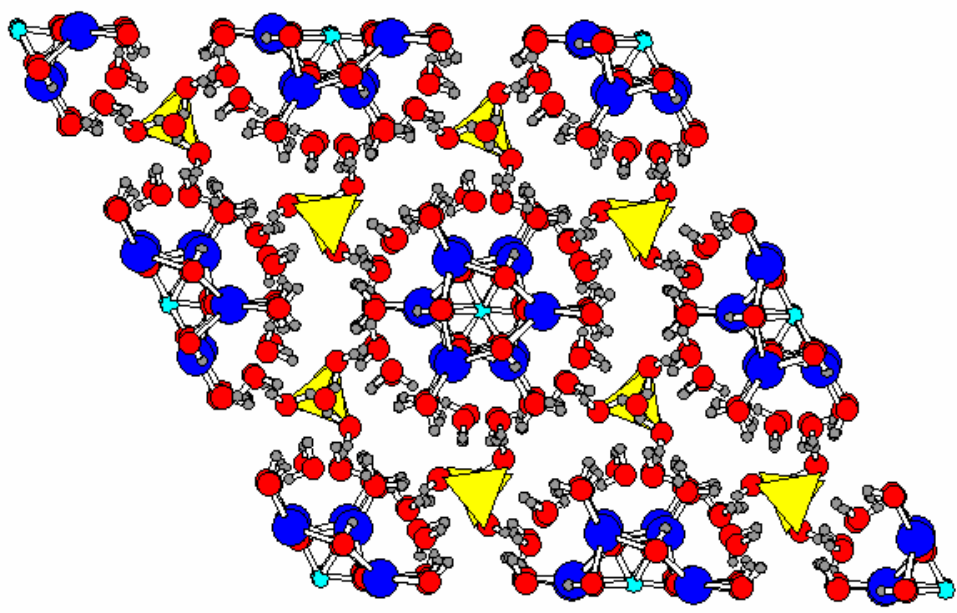


$273 \quad$ Fig. 2

274

\section{Diamond}

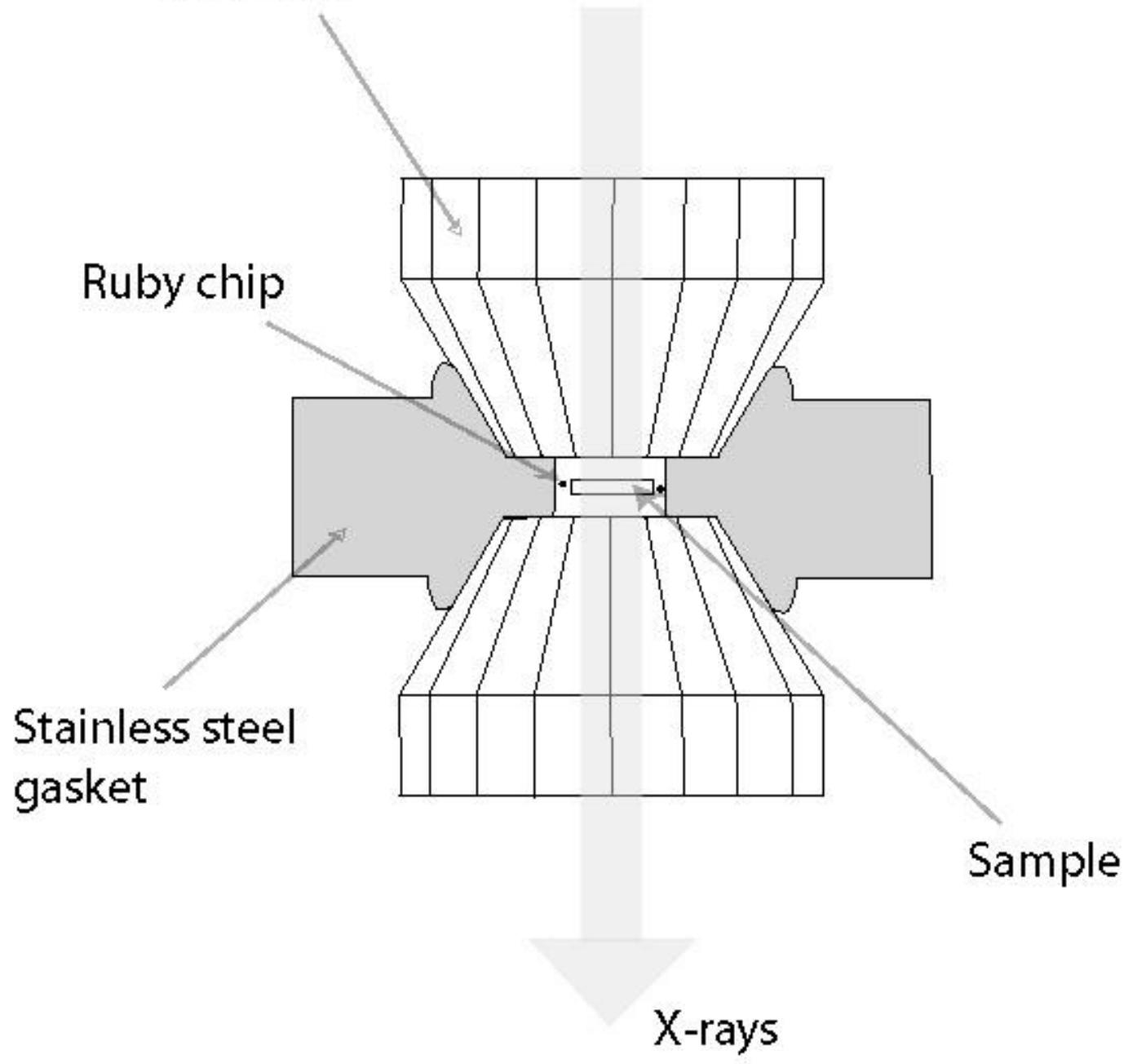

275 
Fig. 3

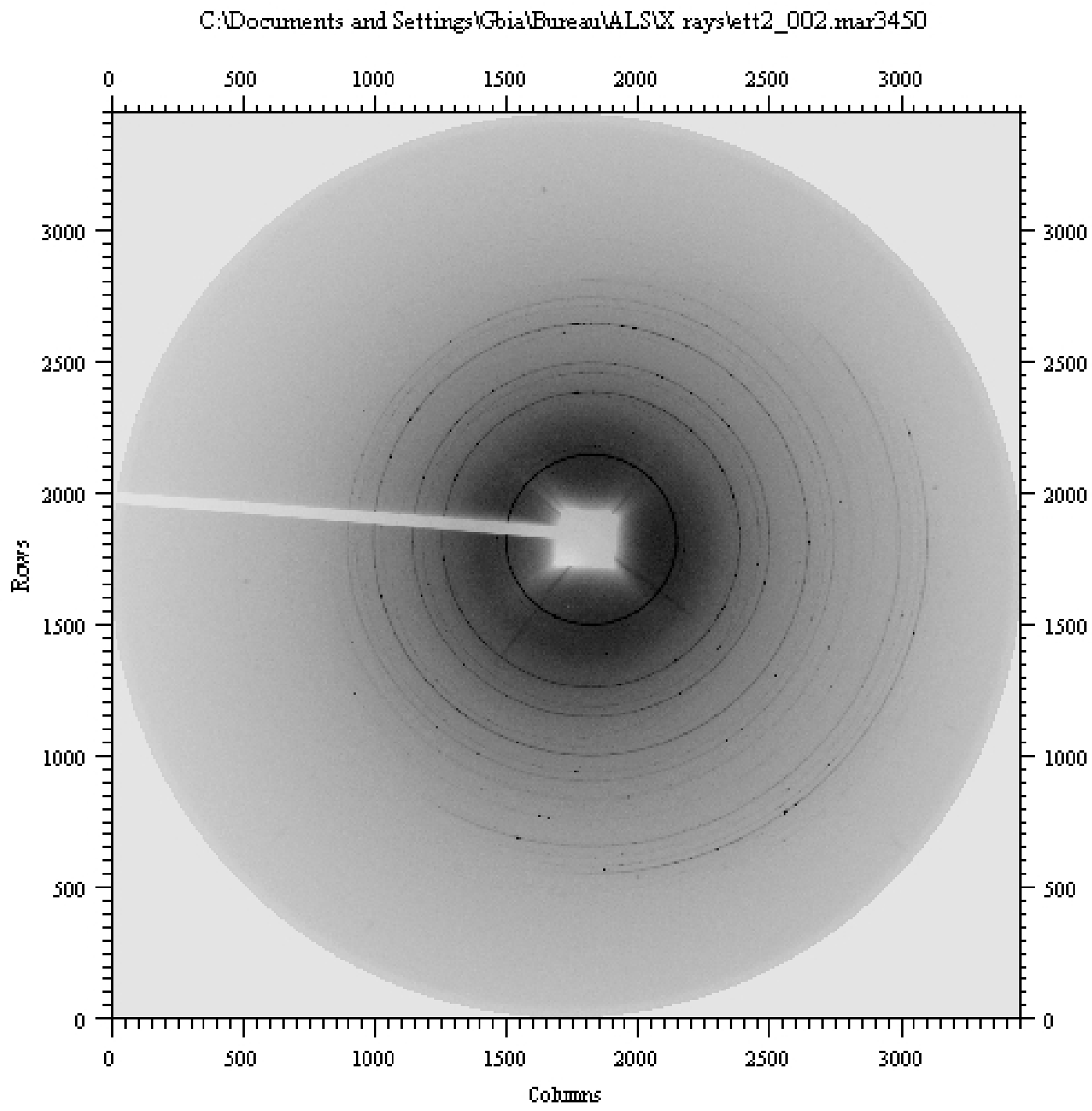

278

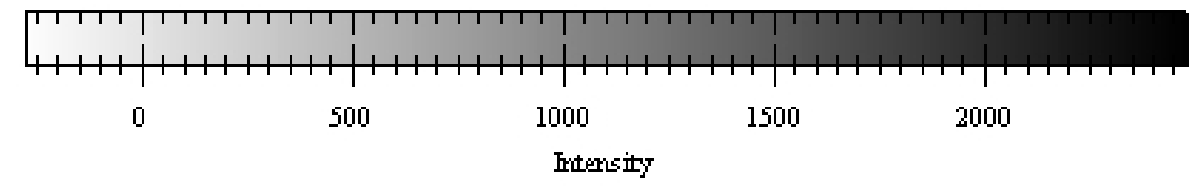


Fig. 4

281

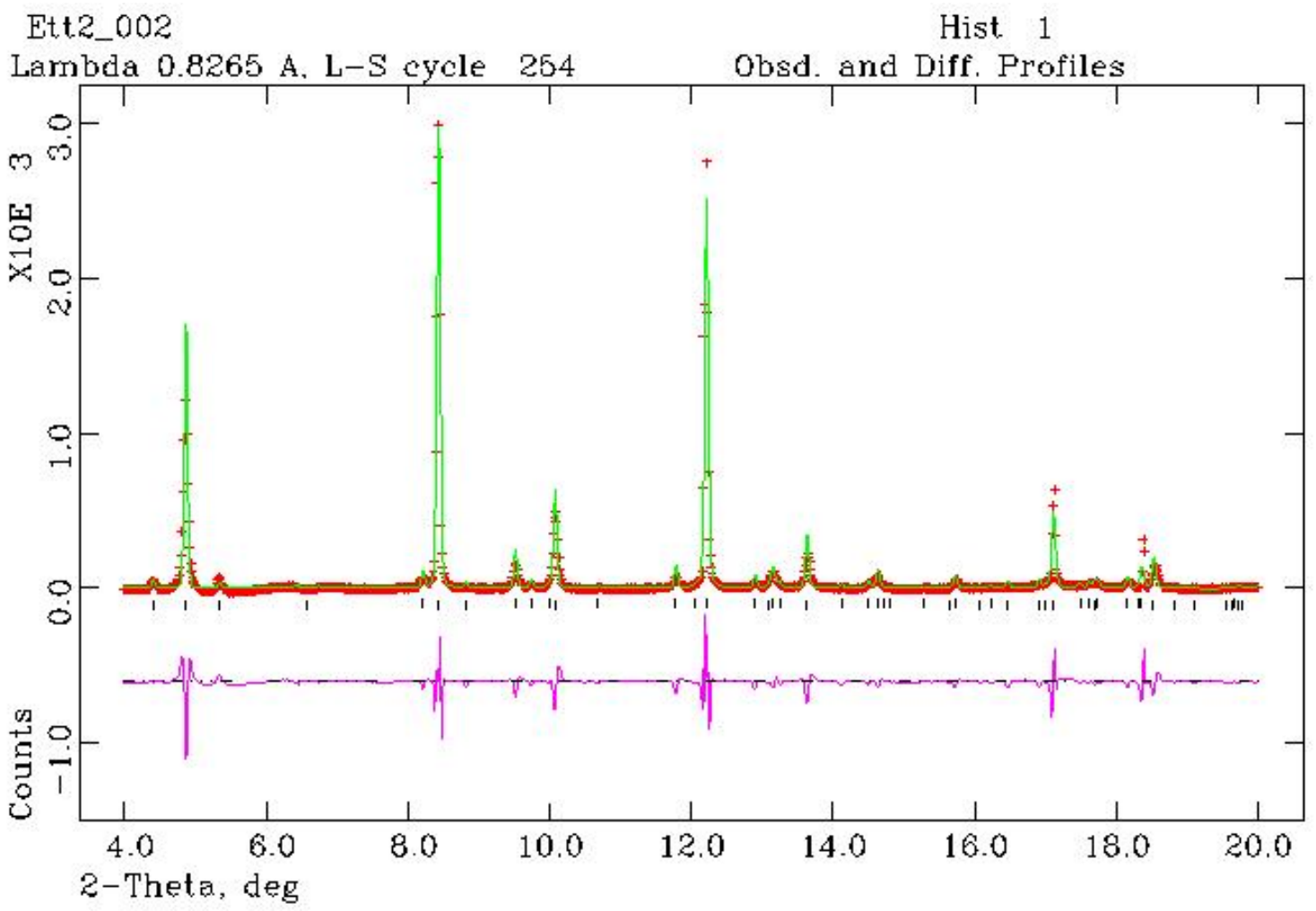

282

283

284 
Fig. 5

286

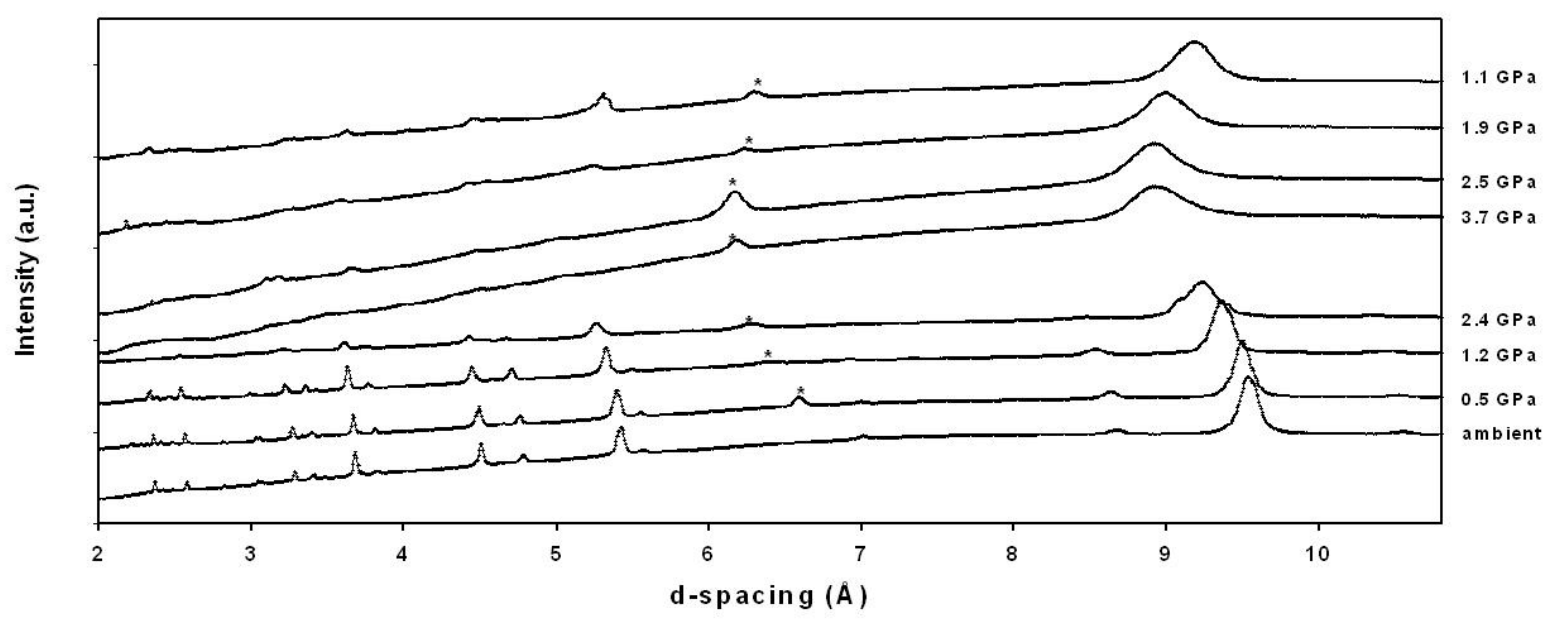


290

Fig. 6a

291

292

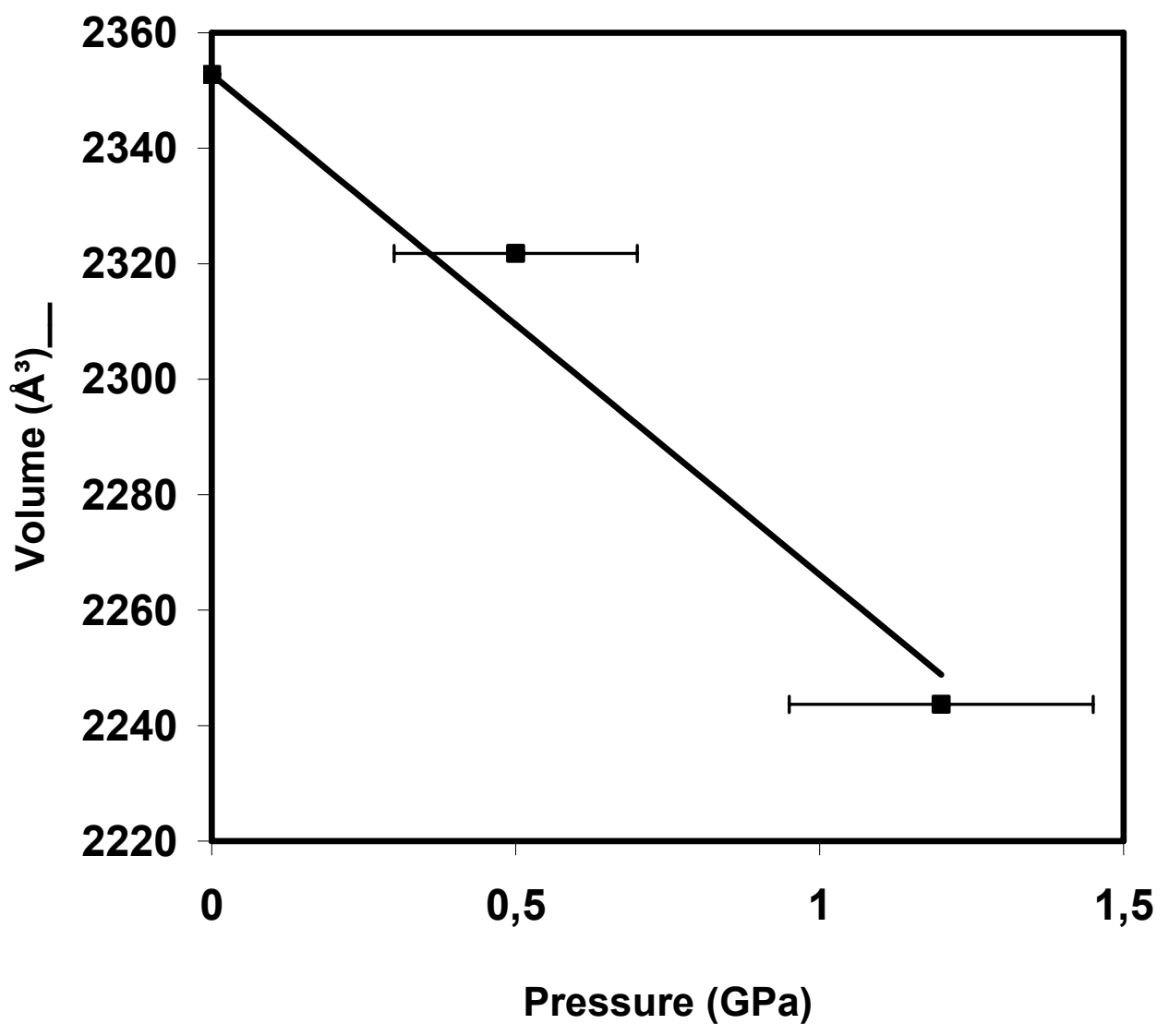

293

294 
295 Fig. 6b.

296

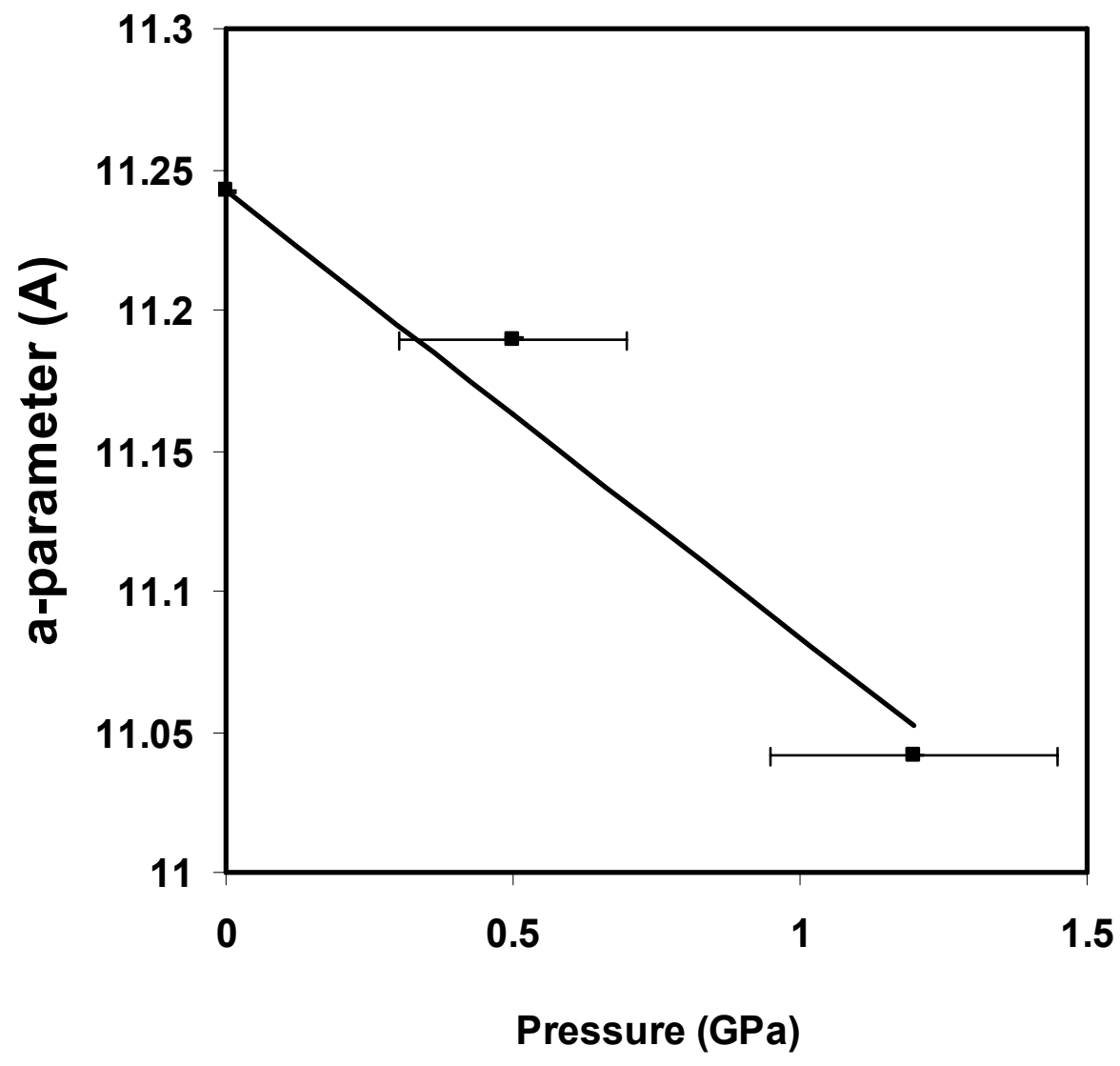


297 Fig. 6c

298

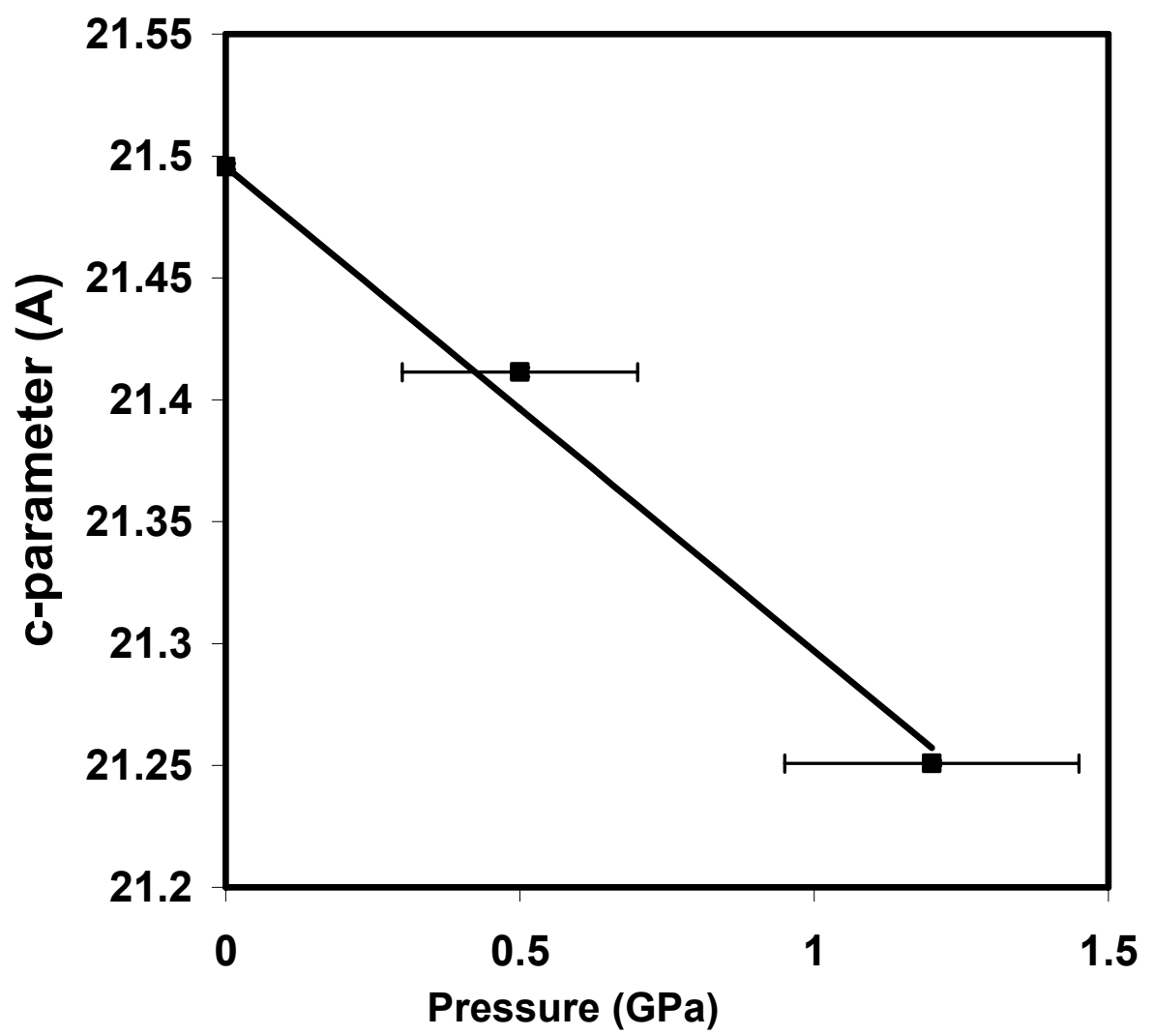


Fig. 7

302

303

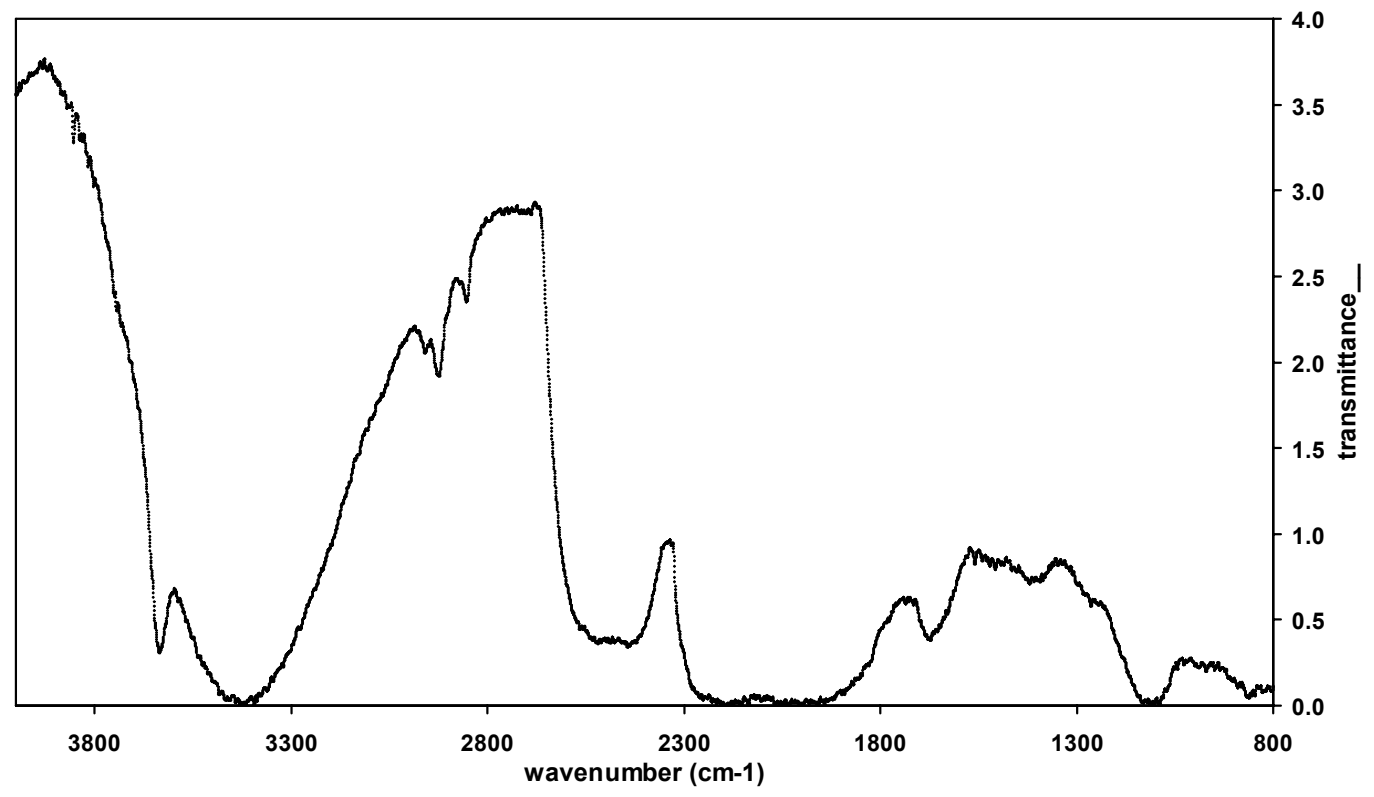


Fig. 8a

306

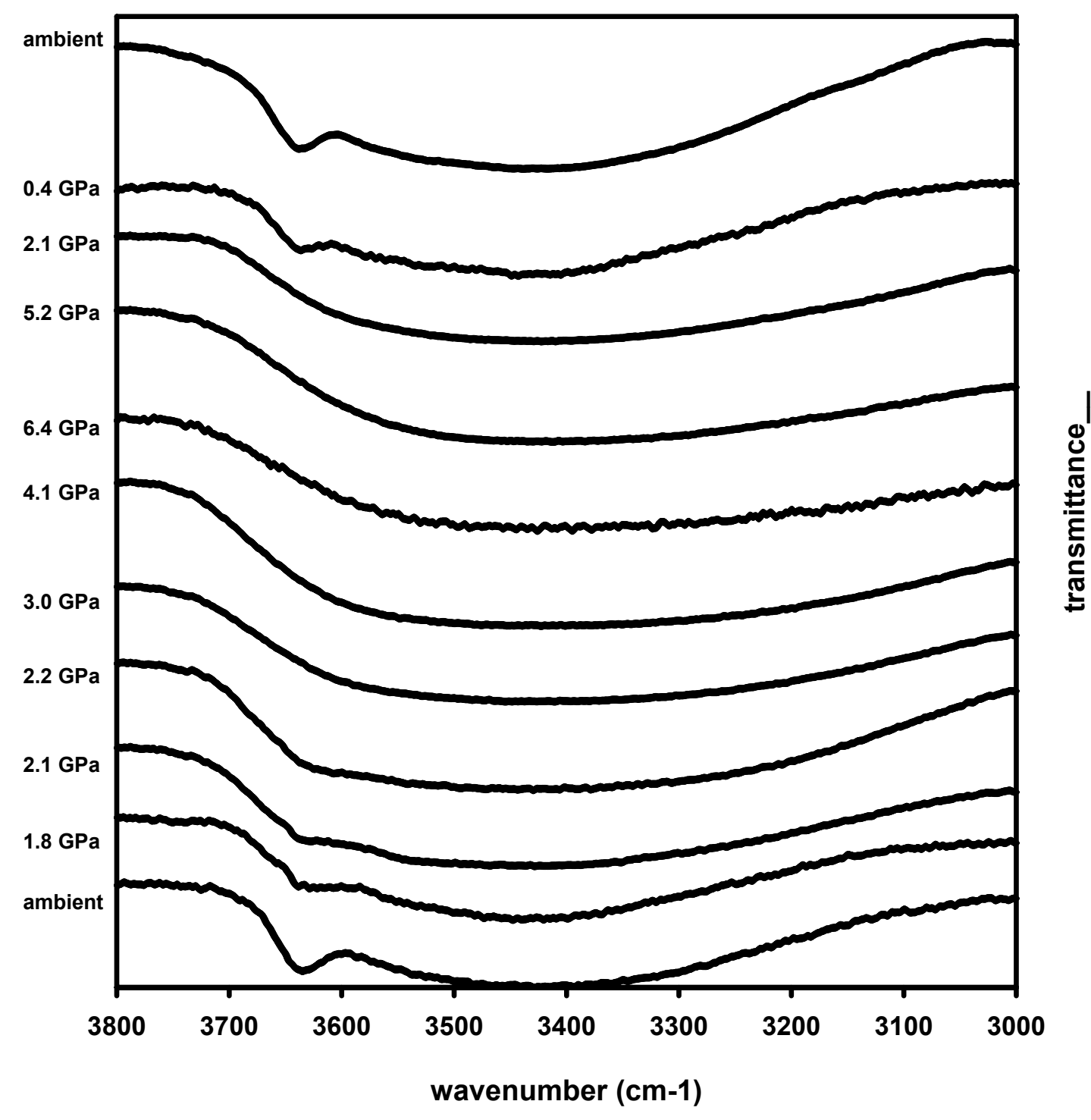


Fig. 8b

310

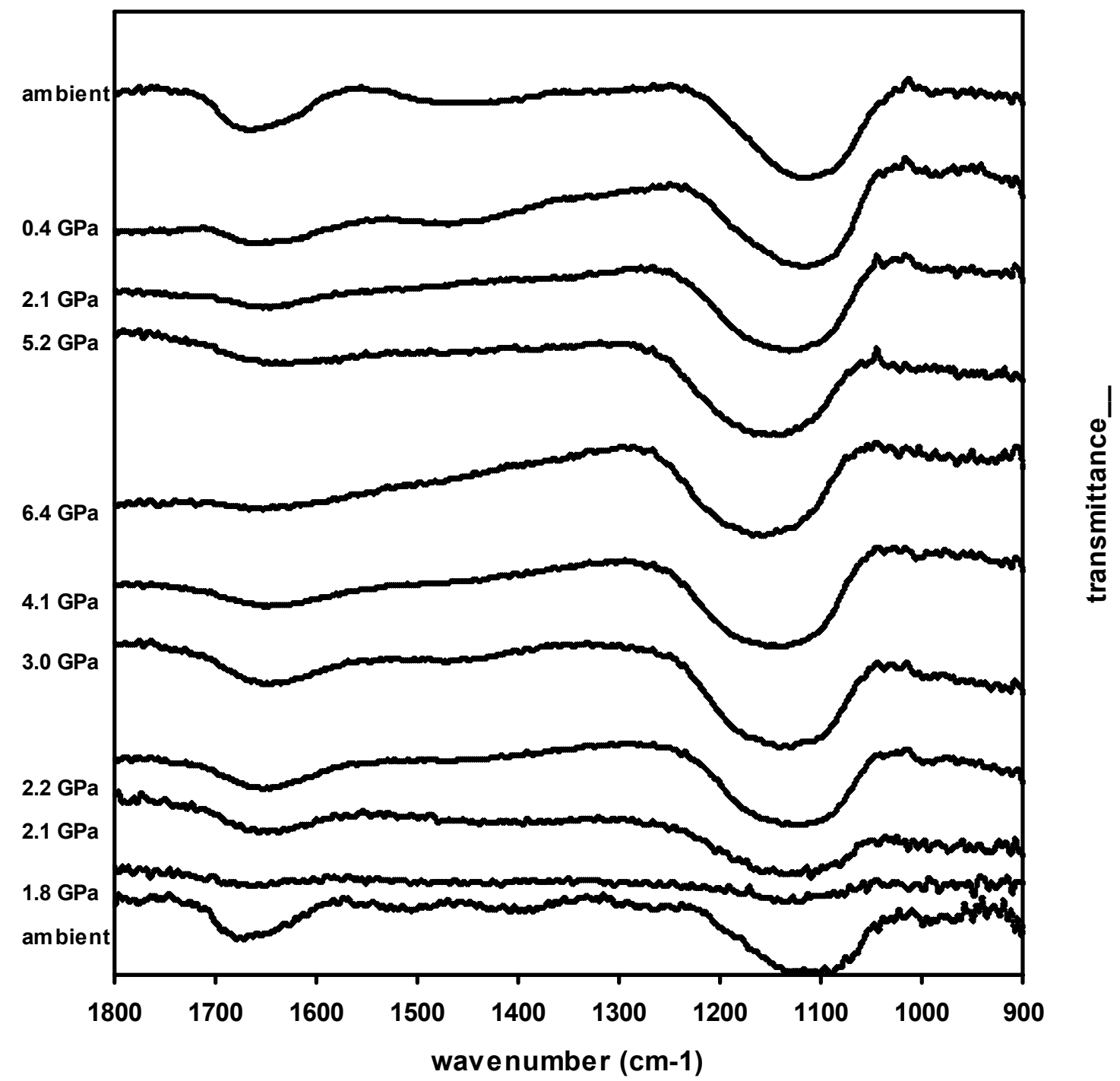


312

$313 \quad$ Fig. 9

314

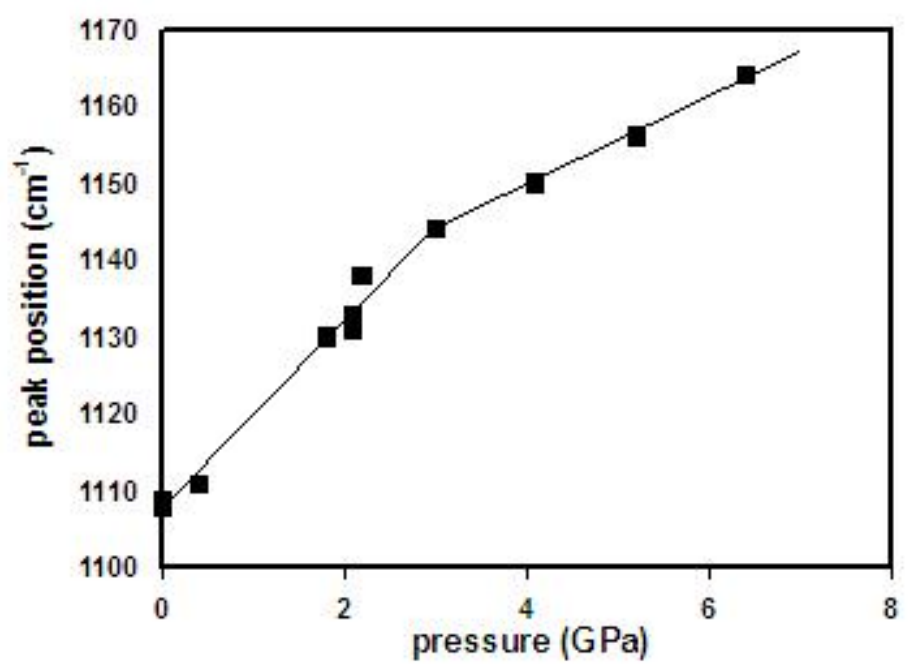

315 
316

317 Table 1.

\begin{tabular}{|l|l|l|l|l|l|l|}
\hline $\begin{array}{c}\text { Pressure } \\
(\mathrm{GPa})\end{array}$ & \multicolumn{1}{|c|}{ Volume $\left(\mathrm{A}^{3}\right)$} & \multicolumn{1}{|c|}{$\mathrm{a}(\mathrm{A})$} & \multicolumn{1}{c|}{$\mathrm{c}(\mathrm{A})$} & $\begin{array}{c}\text { Background } \\
\text { wRp }\end{array}$ & $\begin{array}{c}\text { Background } \\
\mathrm{Rp}\end{array}$ & \multicolumn{1}{c|}{$\mathrm{CHI}^{2}$} \\
\hline $0.0001(0)$ & $2352.8(1)$ & $11.2422(4)$ & $21.496(1)$ & 0.0748 & 0.0484 & 0.8856 \\
\hline $0.5(2)$ & $2321.8(2)$ & $11.1898(5)$ & $21.411(2)$ & 0.0233 & 0.016 & 0.1977 \\
\hline $1.2(3)$ & $2243.7(1)$ & $11.0414(3)$ & $21.251(1)$ & 0.017 & 0.0107 & 0.04819 \\
\hline
\end{tabular}

318

319 